\title{
Structural Changes of the Conditional Volatility of the Portuguese Stock Market
}

\author{
Benilde Maria do Nascimento Oliveira \\ University of Minho, Portugal \\ Manuel José da Rocha Armada \\ University of Minho, Portugal
}

This paper examines the impact of the introduction of the futures market, on the volatility of the underlying Portuguese stock market. The simple analysis of variance is only the first step to a later undertaking of a much more robust methodology which involves the application of a GARCH model, with the main purpose of studying some potential changes on the structure of the conditional volatility of the Portuguese stock market. The results for the Portuguese market are not identical to those generally found internationally. The initial and simple analysis of variance seems to suggest a strong increase in the level of volatility. When a GARCH model is applied, with the main purpose of studying the evolution of the structure of the conditional volatility, a reduction in market efficiency, measured by its ability to quickly incorporate new information, is identified. The replication of the empirical procedures based upon different restricted and consecutive periods of 200 days before and 200 days after of the introduction of PSI-20 index futures market does not, with few exceptions, produce very different conclusions from our initial analysis (JEL: G14, G15).

Keywords: Index futures, conditional volatility, information, GARCH.

\section{Introduction}

The first exchange to trade a stock index futures contract was the Kansas City Board of Trade (KCBT) in 1982, and the underlying index was Value Line Composite Index (VLCI). On the 20th of June of 1996, stock index futures contracts were introduced in Portugal when the

\footnotetext{
* The authors sincerely thank the discussant Rohit Jain at Alabama University and J. Barry Lin at The University of Texas, El Paso, for their useful and constructive comments, at the 2001 Global Finance Conference, Los Angeles, U.S.A. The authors are also grateful for the helpful comments of Professor Chris Adcock and one anonymous referee.
}

(Multinational Finance Journal, 2005, vol. 9, no. 3/4, pp. 189-214)

(C) Multinational Finance Society, a nonprofit corporation. All rights reserved. DOI: $10.17578 / 9-3 / 4-3$ 
Oporto Derivatives Exchange (BDP-Bolsa de Derivados do Porto) started the Portuguese Stock Index (PSI-20) futures transactions.

The impact produced by the introduction of stock index futures on the underlying spot market is a largely documented issue on the context of some important international markets like the USA or UK. For other smaller markets, like the Portuguese stock market, there is a significant lack of empirical studies on this subject. Duque, Ranzina and Sampaio (1998), studied the effects of bond and equities Portuguese futures markets on the volume and volatility of the underlying spot markets. With respect to the Portuguese stock index futures this study is, as far as we know, the first to be made.

The simple analysis of variance is not enough when we want to study the evolution of the mean level and structure of the stock market conditional volatility, after the introduction of futures contracts. In addition to the effective control of the temporal dependency phenomenon, the application of a GARCH model makes possible the explicit treatment of the information and volatility relationship, formulated by Ross (1989). To improve the global quality of the results with regard to some situations, like the departure from the normality assumption or the residual serial correlation, some adjustments/ corrections were made to the used GARCH model.

This paper proceeds as follows: the next section presents a literature review of the previous empirical studies. This is followed by the description of the methodology used. Then, the data used and the empirical results are presented. The final section provides a summary and conclusions.

\section{Literature Review}

Despite the long debate about the issue of stock market volatility, an agreement seems difficult to be reached when it concerns the identification of the sources of volatility, including futures transactions, or even the consequences of an increase in volatility. An increase of the price variability in the stock market can simply reflect a change on the underlying economic context, so it must not be considered, ex-ante, a market destabilizing factor. Stock index futures, because of operational and institutional properties, are traditionally more volatile than spot markets. The close relationship between the two markets makes possible the transference of volatility from futures markets to the underlying spot 
markets. According to the no-arbitrage condition established by Ross (1989), the level of volatility is directly related to the rate of daily information arrival. This way one can think of return volatility as nothing more than a manifestation of information in the markets. If the introduction of a futures market creates special conditions for the dissemination of new information into the markets, then the increase in the volatility in the underlying spot market is a natural consequence.

Previous empirical research, about the impact of the start of an index futures market, on the underlying spot market volatility, has used different methodologies. The simple analysis of variances, linear regression analysis, GARCH models or, marginally, causality analyses, have been the most used methodologies.

Edwards (1988a,b), after examining stock market volatility before and after the start of index futures finds a post-futures volatility decrease for the S\&P 500, but finds no significant change for the Value Line Index. In the same way, Grossman (1988) finds no evidence to support a positive relationship between S\&P 500 futures market activities and the underlying spot market volatility.

To emphasize the fact that the results are highly sensible to the selected time period, Maberly, Allen and Gilbert (1989) use several different time subperiods. If the selected post-futures subperiod is that between the years 1987 and 1988, a significant volatility increase is identified, contradicting Edwards (1988b) previous results. Even so, Maberly, Allen and Gilbert (1989) recognize the fact that a greater volatility for the years of 1987 and 1988 can simply reflect a more accurate information diffusion process.

At the same time, Harris (1989) finds some evidence to support the destabilizing hypothesis for the S\&P 500 index futures market. However, Harris makes clear that other related phenomena, could explain the identified changes. Examining the frequency of jumps in daily stock returns, Becketti and Roberts (1990) do not identify a significant relationship between the existence or the level of activity of the stock index futures market. Bauldauf and Santoni (1991) are among those who conclude for the lack of a destabilizing influence of the index futures transactions on the underlying volatility of the spot market price.

Also with respect to the start of the S\&P 500 index futures market, Brorsen (1991) provides a set of tests for homogeneity of variance and finds that short-term volatility increases (variances of daily price changes) while long-term volatility (variances of 5 and 20 days price changes) does not. Studying another well known index, the Major 
Market Index (MMI), Laatsch (1991) concludes that the volatility of the stocks on the index does not seem to be affected by the index futures market activity.

On the context of Australian market, Hodgson and Nicholls (1991) found that the stock market volatility, measured by the standard deviation of the daily and week returns of the Australian Associated Stock Exchanges All Ordinaries Index (AOI), was not affected by futures transactions. A very interesting investigation was performed by Lee and Ohk (1992) who studied five of the most international index futures market: Sydney, Hong Kong, Tokyo, London and New York. Lee and Ohk identified increases in spot market volatility following the introduction of NIKKEI, FT-SE 100 and VLCI indexes. For the AOI and Hang Seng, no empirical evidence of index futures induced volatility was found. The use of a GARCH model made possible the identification of important efficiency benefits on the markets where the increases of volatility were found. After the start of those index futures markets, the persistence of volatility shocks in the spot market decreased.

Later, Antoniou and Holmes (1995) also considered explicitly the relationship between volatility and information, formulated by Ross (1989). They applied a GARCH model to find that the increase in the mean level of spot volatility, after the start of FT-SE 100 index futures, is explained by a change in the conditional volatility structure. Such a volatility structure change reflects a substantial improvement in the diffusion information process. More recently, Galloway and Miller (1997) also found no evidence of index futures induced price volatility, after studying the effects of the introduction of the MidCap 400 index futures contracts.

Distinguishing between program trading and non-program trading activities, associated to S\&P 500 index futures market, Hogan, Kroner and Sultan (1997) concluded that futures transactions can, in fact, produce a greater spot volatility. However these authors emphasized the idea that such a volatility increase does not necessarily means less efficient prices. Finally, Chatrath, Ramchander and Song (1998) reported a total lack of empirical evidence to support the argument that the number or dimensions of speculative positions in S\&P 500 index futures market produce higher levels of spot volatility.

It is evident that the majority of the several relevant studies mentioned above reject the destabilizing hypothesis as a consequence of the start of index futures markets. In fact, even when some volatility 
increases are clearly identified, such increases are not generally associated with market imperfections. On the contrary, some authors found evidence of positive structure effects on the conditional spot market volatility, after the start of index futures transactions.

\section{The Model and Methodology}

\section{A. Volatility Estimator}

The volatility estimator used on this study is computed from the variance of close-to-close percentage daily price changes, computed by $R_{t}=\ln \left(P_{t} / P_{t-1}\right)$, where $P_{t}$ and $P_{t-1}$ are the closing prices on successive days and $R_{t}$ represents the return in relation to day $t$.

On a simplified way, the level of volatility for the stock market must be understood as being the variance $\sigma^{2}$ of the time series of daily returns:

$$
\sigma^{2}=\frac{\sum_{t-1}^{T}\left(R_{t}-\bar{R}\right)^{2}}{T-1}
$$

where $\bar{R}=\sum_{t=1}^{T} R_{t} / T$ is the arithmetic average of returns.

\section{B. Simple Analysis of Variances}

The first step consisted of performing a simple analysis of variances. The classical volatility estimator previously presented is used to measure the levels of volatility for the Portuguese stock market, with respect to the sub-period before $\left(\sigma_{b}^{2}\right)$ and after $\left(\sigma_{a}^{2}\right)$ the start of the index futures market. After the estimation of the variances, some statistical tests were applied for testing the level of significance of the results with respect to the potential change on the volatility levels, estimated for the two defined sub-periods.

In summary, the null hypothesis $H_{0}: \sigma_{b}^{2}=\sigma_{a}^{2}$ is tested against the alternative hypothesis that the equality is not true. For testing the null hypothesis of equal variances, four tests very commonly used in the literature were applied. The tests are the F-test and the Bartlett test , the Levene test (Levene [1960]) and the modified Levene test (Brown and Forsythe [1974]). 


\section{Estimation of a GARCH Model}

In order to apply GARCH models, we need to accept the volatility clustering hypothesis in relation to the time series of returns under analysis. Graphical analysis and the computation of some basic statistical measures, like the kurtosis or the skewness, can help to provide relevant empirical evidence about the presence of volatility clustering tendencies. Generally, the presence of leptokurtic tendencies on the time series of returns suggests the presence of volatility clustering phenomena on the data, so that the modeling of such phenomena is recommended through the adjustment of autoregressive conditional heteroscedasticity models.

The benefits of the use of GARCH models are not limited to capturing cyclical tendencies exhibited by the time series of financial returns. More importantly, the adjustment of GARCH models makes possible a more complete study of the stock market conditional volatility structure and how that structure may have changed after the introduction of the index futures market. This way, the estimation of a GARCH model offers important advantages when it comes to the empirical analysis of the theoretical relationship, proposed by Ross (1989), between volatility and information.

The following GARCH $(1,1)$ model of Bollerslev (1986) is estimated:

$$
\begin{gathered}
R_{t}=\alpha_{0}+\varepsilon_{t} \\
\varepsilon_{t} \mid \Omega_{t-1} \sim N\left(0, \sigma_{t}^{2}\right) \\
\sigma_{t}^{2}=\alpha_{1}+\beta_{1} \varepsilon_{t-1}^{2}+\theta_{1} \sigma_{t-1}^{2}
\end{gathered}
$$

where equation (4) gives the conditional variance of the spot index daily return $R_{t}$ based on the information set $\Omega_{t}, \mathcal{E}_{t}$ is an i.i.d. error term, $a_{0}$ is a constant for the mean return, $\beta_{1}$ is the coefficient related to past squared errors and represents the impact of recent news on the mean level of volatility, and $\theta_{1}$ is the coefficient associated with the past variance term and measures the impact of less recent news on the mean level of volatility.

In general, and according to past empirical research, the GARCH $(1,1)$ model is able to account for conditional variance of most high 
frequency financial variables. Given this general evidence that the GARCH $(1,1)$ model efficiently represents the wide class of GARCH models ( Bollerslev [1987]), this study also considers the process ( $p=1$, $q=1)$ for the application of the generalized autoregressive heteroscedasticity conditional model. The above model will be estimated by the maximum likelihood method (ML). For the computation of the ML estimates optimization techniques will be used, based upon the BHHH algorithm. ${ }^{1}$

In order to improve the overall quality of the results, whenever it is necessary, some adjustments and/or corrections were applied to the original estimated $\operatorname{GARCH}(1,1)$ model. Such adjustments and/or corrections are related to the normality assumption of the time series of standardized residuals, to the variance equation specification, and to the assumed hypothesis of uncorrelated conditional residuals.

Bollerslev and Wooldrige (1992) suggest an adjustment in the covariance matrix for the computation of robust standard errors, whenever the estimated standardized residuals $\left(\varepsilon_{t} / \sigma_{t}\right)$ do not follow a normal distribution. Therefore, this adjustment validates the inference statistic under the presence of quasi-maximum likelihood (QML) estimators. The distributive properties of the standardized residual series, of the originally estimated GARCH model, must be studied. If we are in the presence of a departure from normality, the model must be estimated again according to the adjustment proposed by Bollerslev and Wooldrige (1992), to ensure the validity of the statistical inference. For that matter, the test suggested by Jarque and Bera (1980) can be computed. Under the null hypothesis of a normal distribution, the Jarque-Bera statistic is chi-squared distributed with two degrees of freedom.

The correct specification of the variance equation of the originally estimated GARCH $(1,1)$ model must be tested by the application of a Lagrange Multiplier test (LM) to the standardized residuals $\left(\varepsilon_{t} / \sigma_{t}\right)$ of the regression. According to Engle (1982), the LM test statistic is the Observed R-squared statistic, computed as the number of observations times the $R^{2}$ from the test regression. The Engle's LM statistic is asymptotically $\chi^{2}$ distributed, with $q$ degrees of freedom, under quite general conditions. LM statistical values larger than the critical values offer evidence of the presence for remaining ARCH (or GARCH) effects. If the variance is correctly specified, there must not remain any

1. Berndt, Hall, Hall and Hausman, 1974. 
autoregressive conditional heteroscedasticity effect in the standardized residuals series, see Greene (1997). If it is not, other GARCH specifications, and not the GARCH $(1,1)$ specification, must be tested until the LM test results are satisfactory. ${ }^{2}$

Finally, the series of standardized residuals is studied with the main purpose to correct for any serial correlation phenomenon. To identify potential effects of serial correlation on the residuals, the Ljung Box Q-statistic (Ljung and Box [1979]) must be computed.

If the series is based upon the results of ARMA estimation then, under the null hypothesis of no autocorrelations up to order $k$ on the standardized residuals, $\mathrm{Q}$ is asymptotically distributed as a $\chi^{2}$ distribution with degrees of freedom equal to the number of autocorrelations. If the Ljung Box Q-statistic results indicate the presence of serial correlation, the GARCH model must be corrected. ${ }^{3}$

Because GARCH models on its original form, assume that the conditional error is serially uncorrelated, some authors recommend the inclusion, of a correction in the conditional mean in order to remove potential correlation from the first order moments of the stock or index returns. According to Scholes and Williams (1978), Bollerslev (1987), French, Schwert and Stambaugh (1987), Lee and Ohk (1992), a potential distortion of the estimated parameters, in the presence of the serial correlation phenomenon, can be avoided by the inclusion of a first order moving average (MA(1)) term in the conditional mean equation.

2. The LM test statistic for the remaining autoregressive conditional heteroscedasticity effects is based upon the computation of an auxiliary test regression. To test the null hypothesis of no remaining autoregressive conditional heteroscedasticity effects up to the order $q$, the follow regression equation must be estimated (Eviews, 1998):

$$
e_{t}^{2}=\beta_{0}+\beta_{1} e_{t-1}^{2}+\beta_{2} e_{t-2}^{2}+\ldots+\beta_{q} e_{t-q}^{2}+v_{t}
$$

where $e_{t}$ represents the standardized residuals of a GARCH $(1,1)$ model. This is a regression of the squared residuals on a constant and lagged squared residuals up to order $q$.

3. The computation of the autocorrelations (AC) and partial autocorrelations (PAC) are extremely useful when we aim to identify autocorrelation patterns for the standardized residual series. The autocorrelation of a series $e$ at lag $k$ is estimated by (Eviews, 1998):

$$
r_{k}=\frac{\sum_{t=k+1}^{T}\left(e_{t}-\bar{e}\right)\left(e_{t-k}-\bar{e}\right)}{\sum_{t=1}^{T}\left(e_{t}-\bar{e}\right)^{2}}
$$

where $\bar{e}$ is the sample mean of $e$. If $r_{1}$ is different from zero, then the standardized residuals series is first order serially correlated. The partial autocorrelation at lag $k, \varphi_{k}$, is the regression coefficient on $e_{t-k}$ when $e_{t}$ is regressed on a constant (Eviews, 1998): $e_{t}=\beta_{0}+\beta_{1} e_{t-1}+\ldots+\beta_{k-1}$ $e_{t-(k-1)}+\varphi_{k} e_{t-k}+$ error. 
Therefore, to ensure the consistency of the estimated parameters, the conditional mean equation (4) is corrected as follows:

$$
\begin{gathered}
R_{t}=\alpha_{0}+u_{t} \\
u_{t}=\varepsilon_{t}+\gamma \varepsilon_{t-1} \quad \text { and } \quad \varepsilon_{t} \mid \Omega_{t-1} \sim N\left(0, \sigma_{t}^{2}\right)
\end{gathered}
$$

\section{Estimation of a Modified GARCH Model}

To study the evolution of the structure of the conditional volatility for the Portuguese stock market as a consequence of the introduction of index futures contracts, a modified GARCH model is used in order to capture a potential change on the structure of the conditional variance of the daily series of returns of the underlying stock market, after the initiation of the transactions in the futures market.

The GARCH modified models belong to a wide category of switching type of models. The switching GARCH models are applied to situations where the coefficients that represent a certain level and autoregressive structure of the conditional volatility in a GARCH model, are constant during a given period of time and then, in a specific moment, significantly change to a new constant level. This way, the use of this kind of models allows the identification of a potential significant impact produced by the introduction of the future contracts, on the conditional volatility of the underlying stock market. The lack of a significant change in the mean level and autoregressive structure of the conditional volatility, allow us to conclude for the absence of a significant impact of the introduction of the index futures market, on the volatility of the underlying market. The next modified GARCH model (Lee e Ohk [1992]), to model the conditional variance can then be estimated:

$$
\begin{gathered}
\sigma_{t}^{2}=\alpha_{1 b}+\beta_{1 b} \varepsilon_{t-1}^{2}+\theta_{1 b} \sigma_{t-1}^{2}\left(t=1,2, \ldots, t^{*}-1\right) \\
\sigma_{t}^{2}=\alpha_{1 a}+\beta_{1 a} \varepsilon_{t-1}^{2}+\theta_{1 a} \sigma_{t-1}^{2}\left(t=t^{*}, t^{*}=1, \ldots, T\right)
\end{gathered}
$$

where, $t^{*}$ represents the switching point, in this particular case, the listing date of the stock index futures. Since the date $t^{*}$ is well known, the equations (10a) and (10b) can be represented by one equation with a dummy variable: 


$$
\sigma_{t}^{2}=\alpha_{1 b}+\beta_{1 b} \varepsilon_{t-1}^{2}+\theta_{1 b} \sigma_{t-1}^{2}+\alpha_{1 d} D_{t}+\beta_{1 d} \varepsilon_{t-1}^{2} D_{t}+\theta_{1 d} \sigma_{t-1}^{2} D_{t}
$$

where $D_{t}$ is a dummy with the value of 0 if $1 \leq t \leq t^{*}-1$, and the value of 1 if $t^{*} \leq t \leq T$;

$$
\alpha_{1 d}=\alpha_{1 a}-\alpha_{1 b}, \beta_{1 d}=\beta_{1 a}-\beta_{1 b},
$$

and

$$
\theta_{1 d}=\theta_{1 a}-\theta_{1 b}
$$

If the start of trade in stock index futures does not produce a significant change in the autoregressive structure $\left(\beta_{1 d}\right.$ and $\left.\theta_{1 d}\right)$ of the underlying stock market conditional volatility, then, the coefficients associated with these two dummy variables will not be significantly different from zero.

\section{Data}

A. The Proxy Used for the Estimation of the Conditional Volatility of the Portuguese Stock Market

The PSI-20 index is used as a proxy to estimate the volatility of the Portuguese stock market for the chosen time period. The PSI-20 is well known and largely used as a benchmark for Portuguese stock market. It represents the actual value of a portfolio with 20 stock issues bought in a specific past moment, particularly the close of the stock exchange on December the 31st of 1992 . The closing daily data in relation to PSI-20 index, for the period under analysis, were collected from the Oporto Derivatives Exchange.

\section{B. The Periods and Sub-periods of Analysis}

A very significant part of this study relies on a global time period defined from December the 31st of 1992 until December the 31st of 1998. The definition of this large time period was conditioned for two main factors:

The daily PSI-20 index prices are only available since December the 31st of 1992, which is the date of the base value of the index.; 
Including as many observations as possible to improve the consistency of this study.

The global time period under analysis will then be divided up into two subperiods, based on the starting date of the PSI-20 index futures market (as previously mentioned: the 20th of June of 1996).

The importance of considering this period and subperiods of time is directly related with the adoption of a long term perspective. In order to the results be more robust, when it comes to the identification of the potential stabilizing/destabilizing impact eventually produced by the start of index futures transactions on the spot underlying market, a representative data sample is necessary. Nevertheless, one important limitation, when the proposed methodologies were applied, was that other economic factors that may influence the value of the index were not taken into account. Therefore, a new attempt was made to clarify the impact produced by the introduction of the PSI-20 index futures market. Such an attempt consisted on performing the same kind of analysis but now based on the definition of several shorter periods of time of 400 days of transactions (200 days before and 200 days after the introduction of futures market). Specifically, the period after the introduction of futures market of about one year and a half was firstly divided up into three subperiods of about 200 days of transactions each. Then, we tested the presence of significant changes on the structure of Portuguese stock market conditional volatility after the beginning of the futures market with respect to each of those subperiods against the subperiod of 200 days of transactions before the introduction of PSI-20 index futures market.

\section{Empirical Results}

\section{A. Analysis of Variance}

The first results in relation to the analysis of variance suggest an increase of the mean level of the volatility for the Portuguese stock market, after the introduction of the PSI-20 index futures market on the 20th of June of 1996 (Table 1). The results of the different statistical 


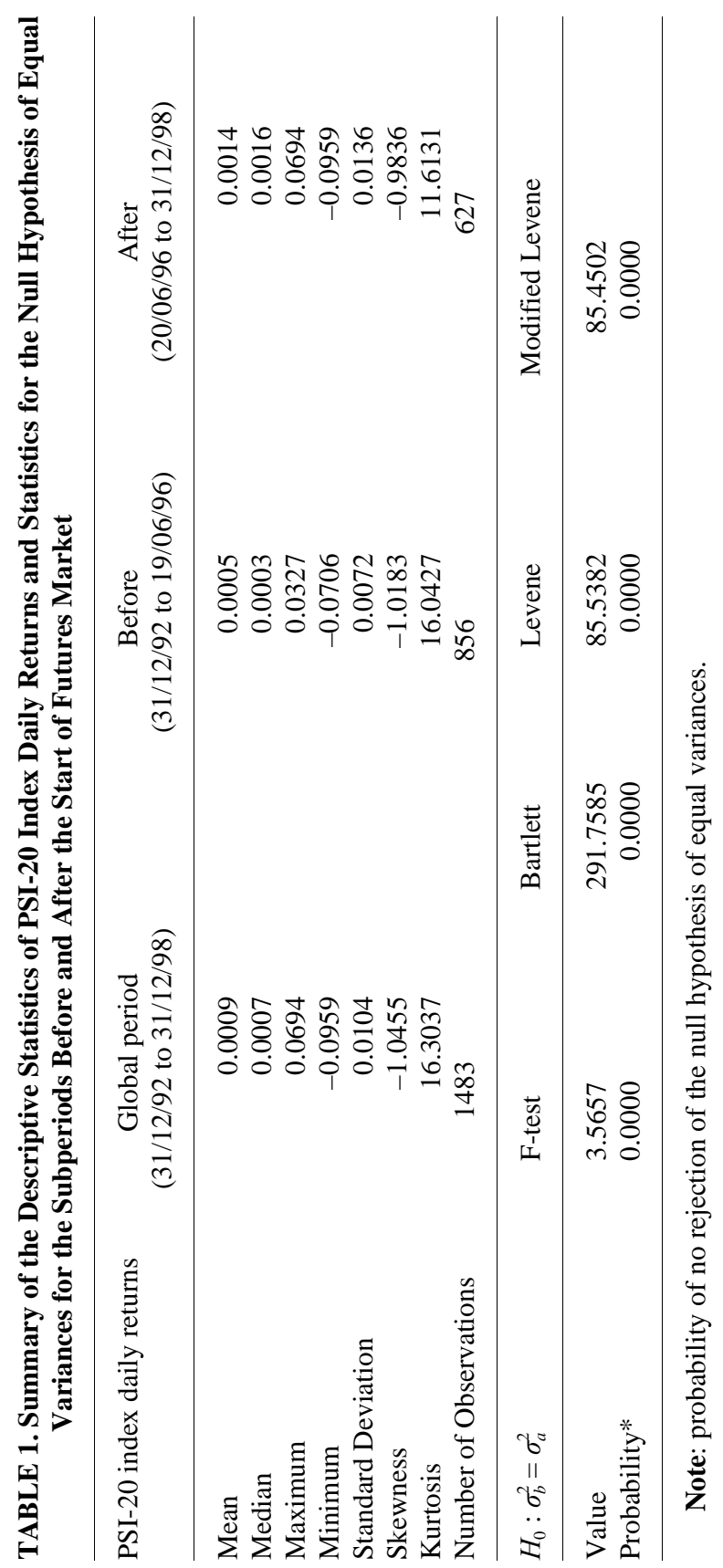




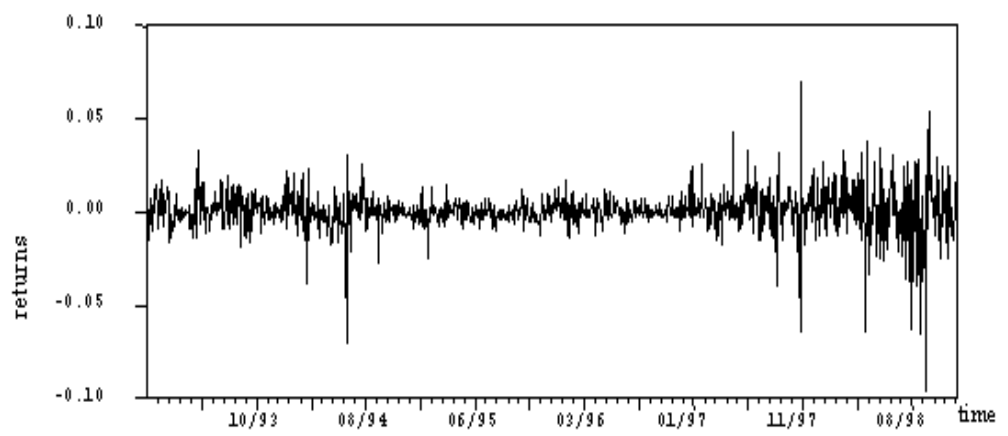

FIGURE 1-PSI-20 index daily returns:31/12/92 to 31/12/98

tests applied are identical when it turns out to reject the null hypothesis of equal variances for the two subperiods under analysis (table 1).

\section{B. Estimation of a Modified GARCH Model}

The presence of temporal dependency in the time series of daily returns of the PSI-20 index was identified by the computation of the kurtosis and of the skewness for the global time period considered (table 1), as well as via a graphical analysis (see figure 1). After the identification of temporal dependency, the conditional volatility of the PSI-20 index of the time series of daily returns can be modeled by the application of a GARCH $(1,1)$ model.

The normality hypothesis for the standardized residuals of the estimated model was rejected, $99 \%$ level of confidence according to the Jarque-Bera statistic (see appendix). As a consequence, the model was estimated using the adjustment proposed by Bollerslev and Wooldrige (1992). The use of such an adjustment, as previously mentioned in section II, will enable us to produce robust standard errors in the presence of a departure from the normality hypothesis. On the other hand, no remaining effects of autoregressive conditional heteroscedasticity was identified by the application of the LM test, so the GARCH $(1,1)$ model was considered to be representative of the behaviour of the financial series under analysis (see appendix). Finally, and as the result of the Ljung Box Q-statistic indicated the presence of serial correlation in the residuals (see appendix), the modified model 


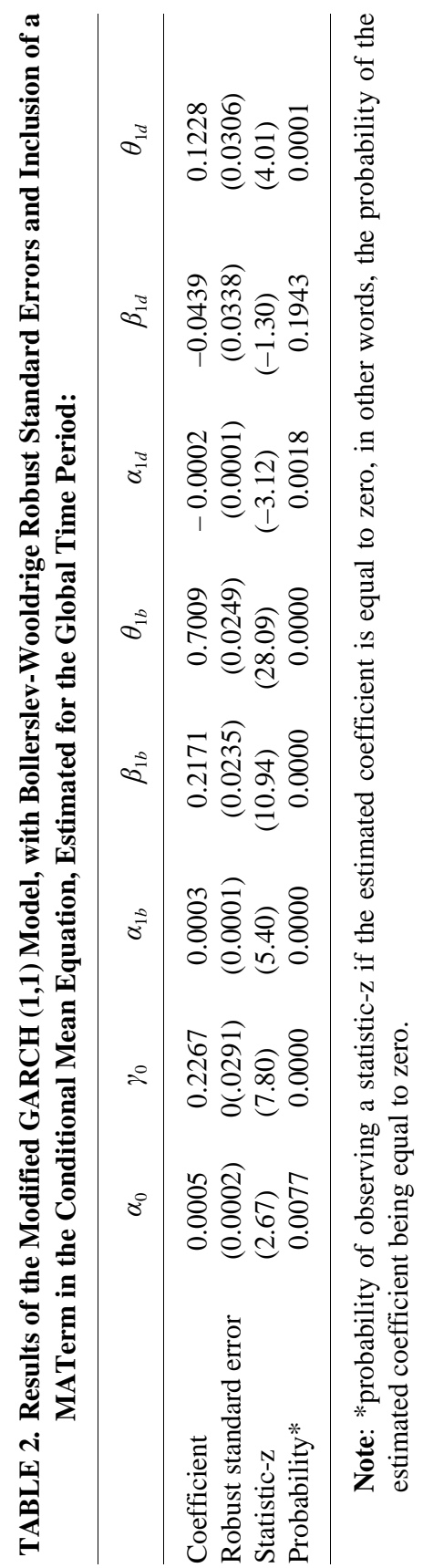


was estimated with the inclusion of a MA term of first order on the equation of the conditional mean.

After adjusting the GARCH $(1,1)$ model to best represent the behaviour of the PSI-20 daily returns, the modified GARCH model was then estimated. The results are summarized on table 2 .

All the parameters are statistically significant for a 95\% level of confidence, with the exception of the dummy coefficient designed to identify a potentially significant change on the contribution of the $\mathrm{ARCH}$ term to the conditional volatility structure $\left(\beta_{1 d}\right)$, for the subperiod after the start of futures market.

As it is well known, on the context of the GARCH models framework, the mean of the conditional variance is by definition the unconditional variance. In accordance to the previous results from the simple analysis of variances, the unconditional variance generally given by $\alpha_{1} / 1-\beta_{1}-\theta_{1}$ ) seems to increase after the start of futures market. ${ }^{4}$ Based on our estimates, we have an unconditional variance of approximately 0.0037 before the introduction of PSI-20 index futures market and 0.0323 after the start of futures market.

On the other hand, the $\beta_{1 d}$ coefficient, designed to measure a potential change in the first order autoregressive structure is negative. This coefficient is not statistically different from zero for a $95 \%$ level of confidence, which can be interpreted as a lack of significant change on the first order autoregressive structure of the squared residuals. The coefficient, $\theta_{1 d}$ designed to identify a potential structural change of the effect of the conditional volatility in moment $t-1\left(\sigma_{t-1}^{2}\right)$ on the conditional volatility of moment $t\left(\sigma_{t}^{2}\right)$ after the start of the PSI-20 index futures market, is significantly positive. This fact reveals that the importance of past conditional volatility for the explanation of present volatility increases, for the subperiod after the introduction of the futures market. Because $\theta_{1 d}$ is the coefficient on the lagged variance term, it can be interpreted as reflecting the impact of "old news" on the definition of present conditional volatility. As "old news" increases significantly its impact on today's price changes, conditional volatility structure is said to become less efficient as information becomes more persistent in time.

This conclusion is given further support by the fact that the value of $\beta_{1}+\theta_{1}$ becomes closer to the unity after the introduction of index

4. Before and after the introduction of futures markets the unconditional variance is respectively given by: $\alpha_{1 b} / 1-\beta_{1 b}-\theta_{1 b}$ and $\alpha_{1 a} / 1-\beta_{1 a}-\theta_{1 a}$. 


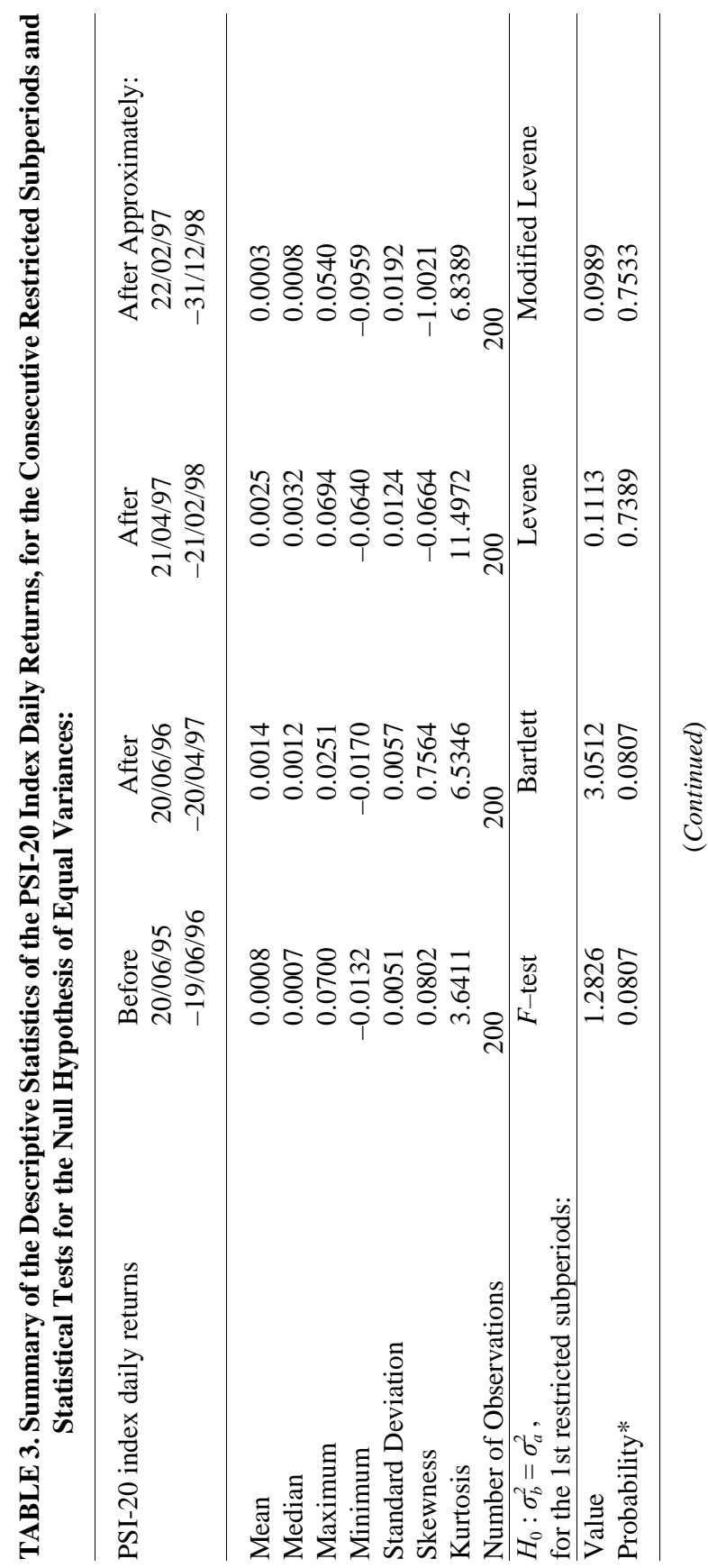




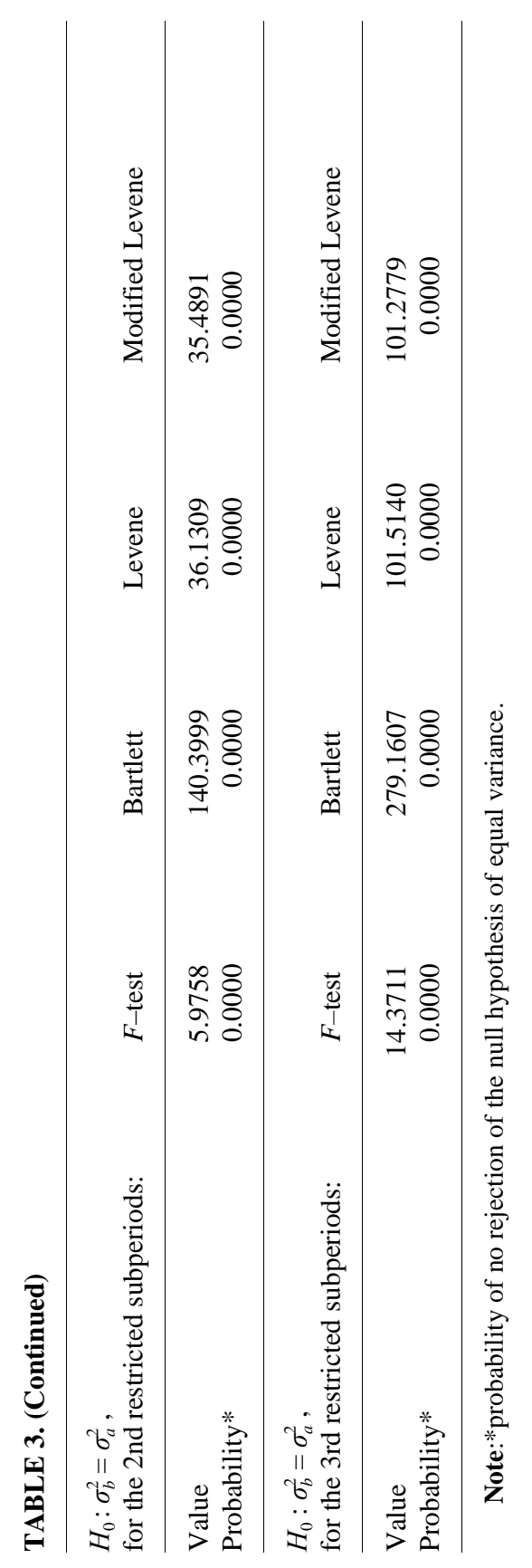


futures market $\left(\beta_{1 b}+\theta_{1 b}=0.9180\right.$ and $\left.\beta_{1 a}-\theta_{1 a}=0.9969\right)$.

D. Empirical Results of the Replication of the Previously Used Methodologies Based Upon Three Different Restricted Time Periods

The results previously reported for the simple analysis of variance or, even, for the application of the GARCH methodology, were based upon the global period of analysis that spans from 31st of December of 1992 to 31 st of December of 1998.

Now, three restricted periods of 400 days of transaction will be considered. Firstly, a restricted subperiod of 200 days of transaction immediately before the beginning of PSI-20 index futures market was considered. Then, the period of time after the beginning of futures market, from the 20th of June of 1996 to the 31st of December of 1998, was divided up into three restricted subperiods of 200 days each. Finally, the hypothesis of significant changes on the volatility was tested by comparing each one of these three restricted subperiods after the beginning of futures market with the restricted subperiod before the introduction of index futures transactions. The results with respect to the three restricted periods are presented next. Table 3 summarizes the main descriptive statistics before and after the start of the PSI-20 index futures market, with respect to the three restricted periods under analysis, as well as the results for the statistical tests for the null hypothesis of equal variances with respect to the three consecutive restricted subperiods previously defined.

For the first restricted period considered, the standard deviation slightly increases after the start of the futures transactions, suggesting an increase of the volatility level in the Portuguese stock market in relation to these 200 days period. Considering the second restricted and consecutive period we can identify an even stronger increase of the standard deviation. Finally, for the third restricted and consecutive period the standard deviation also increases after the introduction of futures market. With respect to the first two subperiods before and after the introduction of the PSI-20 index futures, the results of the F-test and of the Bartlett test, for a $90 \%$ level of confidence, indicate the rejection of the null hypothesis of equal variances. However, the results of the Levene and Modified Levene test are different, indicating that for a 95\% level of confidence one cannot reject the null hypothesis that the level of volatility is identical for the two subperiods. For a $99 \%$ level of confidence, in relation to all tests, and for the second and third restricted 
periods considered, one can reject the null hypothesis that the level of volatility is identical for the two subperiods, before and after the start of PSI-20 index futures market.

The values for the kurtosis and skewness, computed for the four restricted subperiods (one before and three after the introduction of the futures market), indicate the presence of some leptokurtic tendency that can be modeled by the use of a GARCH model. Again, a GARCH $(1,1)$ model was estimated and adjusted to best represent the behaviour of the studied variable. ${ }^{5}$

This kind of procedure will enable us to continue our study about the evolution of the structure of the conditional volatility of the Portuguese stock market. The results for the estimation of the modified GARCH model on the context of the three restricted periods of analysis are summarized on table 4.

For the first restricted period of analysis, all the parameters associated with the dummies in the variance equation are statistically significant for a $95 \%$ level of confidence, with the exception of the dummy coefficient designed to identify a potentially significant change on the contribution of the GARCH term to the conditional volatility structure $\left(\theta_{1 d}\right)$.

The $\beta_{1 d}$ coefficient, designed to measure a potential change in the first order autoregressive structure is significantly positive. This fact reveals that recent information, represented by the first order autoregressive structure of the squared residuals, became more important on the explanation of the present market volatility. Hence, $\beta_{1 d}$ relates to the impact of "recent news", its higher value for the first restricted subperiod after the introduction of index futures market implies that recent news increases its impact on the explanation of present price changes. The $\theta_{1 d}$ coefficient, designed to identify a potential structural change of the effect of the conditional volatility in moment $t-1\left(\sigma_{t-1}^{2}\right)$ on the conditional volatility of moment $t\left(\sigma_{t}^{2}\right)$ after the start of the PSI-20 index futures market, is not significantly negative. Generally speaking, as $\beta_{1}+\theta_{1}$ becomes closer to the unity after the start of futures market, an increase in the persistence of information can be identified considering this first restricted time period.

For the second restricted period of analysis, all the dummies are statistically significant for a $95 \%$ level of confidence, again with the exception of the dummy coefficient associated with the GARCH term

5. The results for the diagnostic tests are available upon request. 


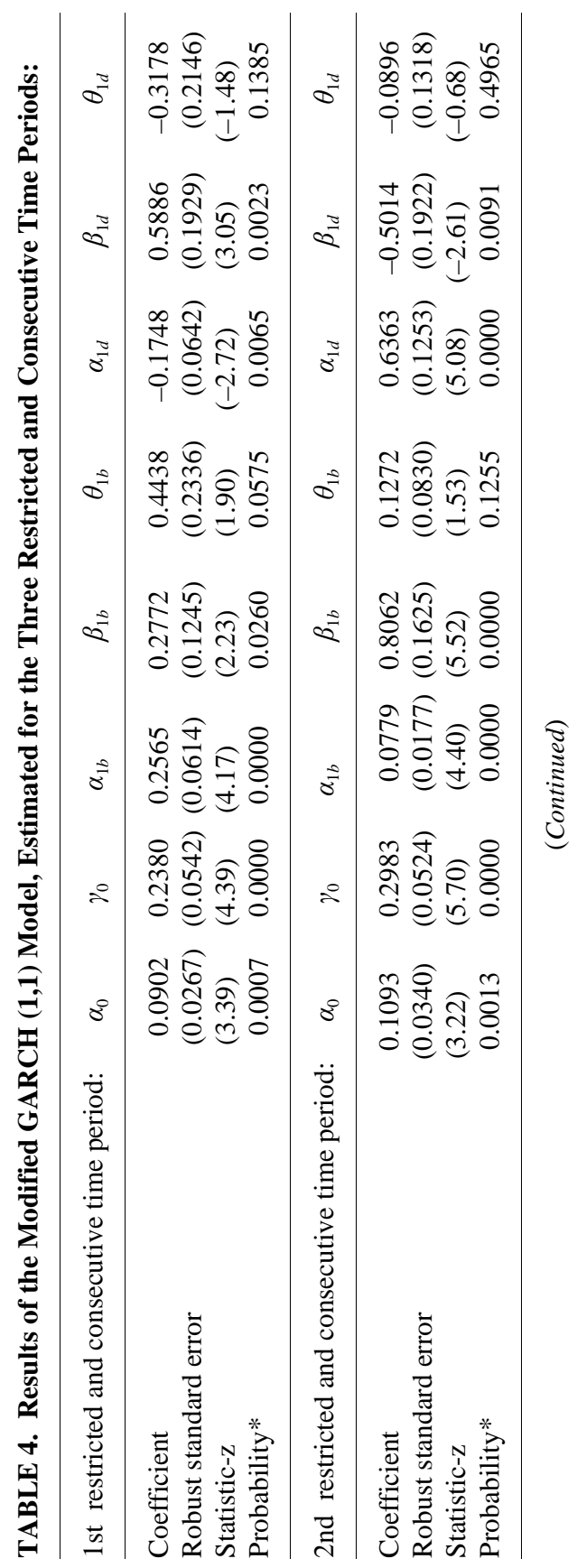




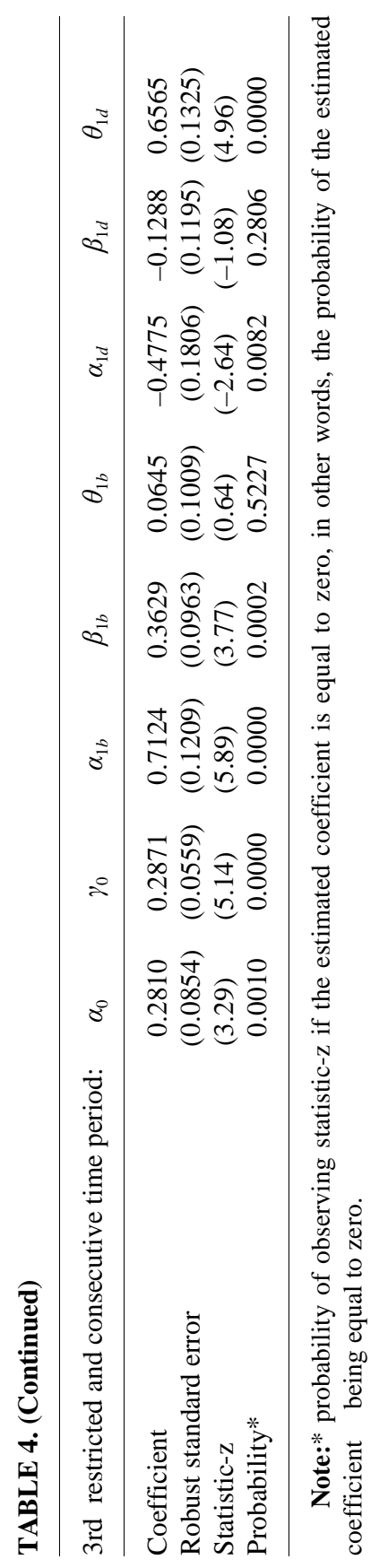


$\left(\theta_{1 d}\right)$. In terms of the conditional volatility structure, the results for this second restricted and consecutive period of analysis are quite different from those obtained for the global period. In fact, with respect to the global period and as $\beta_{1}+\theta_{1}$ becomes closer to the unity after the start of index futures trading, we can point out an increase in persistence of information. Considering this second restricted period of analysis no increase of persistence is identified. On the contrary, $\beta_{1}+\theta_{1}$ becomes more distant from the unity, after the start of index futures market. The $\beta_{1 d}$ coefficient, designed to measure a potential change in the first order autoregressive structure is significantly negative. This time, after the introduction of PSI-20 index futures market, recent information became less important on the explanation of present volatility. The $\theta_{1 d}$ coefficient, is also negative but without statistical meaning.

Finally, for the third restricted period of analysis, all the parameters associated with the dummy variables are statistically significant for a 95\% level of confidence, with the exception of the dummy coefficient designed to identify a potentially significant change on the contribution of the ARCH term to the conditional volatility structure $\left(\beta_{1 d}\right)$. The $\beta_{1 d}$ coefficient, designed to measure a potential change in the first order autoregressive structure is negative. However, the value of this coefficient is not statistically different from zero for a $95 \%$ level of confidence, which can be interpreted as a lack of significant change on the first order autoregressive structure of the squared residuals. On the other hand, the coefficient is significantly positive, which means that for the third subperiod after the beginning of futures transactions, past volatility became more important on the definition of present volatility. Once again, we can find that, after the introduction of PSI-20 index futures trading, information becomes more persistent in time as the impact of "old news" increases after the start of futures market and $\beta_{1}$ $+\theta_{1}$ becomes closer to the unity after the start of futures transactions.

\section{Concluding Remarks}

Since the start of the index futures transactions, in the eighties, it has been frequently argued that this was the cause of an increase of the volatility of the underlying spot markets. The main purpose of this study was to offer an additional contribution in order to help clarifying this question, by examining the impact produced by the introduction of PSI-20 index futures market on the mean level and structure of the 
Portuguese stock market conditional volatility.

A large time period was initially chosen for that matter. The initial and simple analysis of variance, with regard to the two subperiods, before and after the introduction of the futures contracts, seems to suggest a strong increase in the level of the volatility. When the temporal dependency phenomenon is modeled, again an increase on the mean level of the unconditional volatility seems to be identified for the subperiod after the introduction of PSI-20 index futures. Such an increase is apparently followed by a reduction in market efficiency, measured by its ability to quickly incorporate new information. In fact, after the introduction of the PSI-20 index futures, volatility shocks became more persistent in time. The results for the Portuguese market are not in accordance with the majority of the international studies because we cannot identify an improvement on market efficiency as a consequence of the start of futures transactions. On the contrary, Portuguese stock market seemed to become less efficient as the volatility shocks became more persistent after the start of PSI-20 index futures market. This fact is further supported by the value of the persistence coefficient $\theta_{1 d}$ associated with the dummy in the modified GARCH variance equation and also by the evolution of the value of $\beta_{1}+\theta_{1}$ that becomes very close to the unity after the introduction of futures market.

The replication of the previous empirical procedures, based upon three different restricted and consecutive periods of analysis, in general, allows us to corroborate the results obtained for the global period of analysis. In fact, with the exception of the second restricted period, the study of the structure of the conditional volatility of the Portuguese stock market, before and after the introduction of PSI-20 index futures trading, enable us to conclude that, after the start of index futures market, the underlying stock market became less efficient as the volatility shocks became more persistent in time. The results for the second restricted and consecutive period of analysis are assumed to be an exception in terms of both the two other previously defined restricted periods and the global period of analysis initially used.

One final note to emphasise the fact that our results should be cautionary taken into account due to some limitations, such as the lack of control for eventual other influences, apart from the introduction of the index futures market, and the relative maturity of the Portuguese futures market, which is a relatively recent market.

The explicit control of other economic influences, the use of 
multivariate models when the hypothesis of cointegration between the prices of the futures and the spot market is proven (e.g. Cheung and Fung, 1997), or even the consideration of asymmetric conditional volatility models are good examples of relevant directions for future research.

\section{Appendix - Statistics Based on the GARCH(1,1) Standardized Residuals}

A. Descriptive Statistics

$\begin{array}{lr}\text { Mean } & 0.0557 \\ \text { Median } & 0.0484 \\ \text { Maximum } & 6.0209 \\ \text { Minimum } & -5.2806 \\ \text { Standard deviation } & 0.9990 \\ \text { Skewness } & 0.1104 \\ \text { Kurtosis } & 6.1004 \\ \text { Jarque-Bera Statistic } & 0.0000 *\end{array}$

B. LM Test Statistics for GARCH Effects

Obs $*$ R-squared $\quad 7.8325 \quad 0.2506^{*}$

C. Ljung-Box Statistic (LB)

$\begin{array}{lclccc}\text { Order } & \text { LB } & \text { Prob } & \text { Order } & \text { LB } & \text { Prob } \\ 1 & 84.87 & 0.0000 & 11 & 149.92 & 0.0000 \\ 2 & 109.02 & 0.0000 & 12 & 151.13 & 0.0000 \\ 3 & 118.05 & 0.0000 & 13 & 151.58 & 0.0000 \\ 4 & 123.80 & 0.0000 & 14 & 153.13 & 0.0000 \\ 5 & 125.53 & 0.0000 & 15 & 157.45 & 0.0000 \\ 6 & 125.79 & 0.0000 & 16 & 158.04 & 0.0000 \\ 7 & 134.34 & 0.0000 & 17 & 158.57 & 0.0000 \\ 8 & 138.16 & 0.0000 & 18 & 161.90 & 0.0000 \\ 9 & 140.50 & 0.0000 & 19 & 162.05 & 0.0000 \\ 10 & 144.04 & 0.0000 & 20 & 163.20 & 0.0000\end{array}$

Note: Prob or * is for probability of no rejection of the null hypothesis.

\section{References}

Antoniou, A., and Holmes, P. 1995. Futures trading, information and spot price volatility: Evidence for the FTSE-100 Stock Index Futures contract using 
GARCH. Journal of Banking \& Finance 19 (April): 117-129.

Bauldof, B., and Santoni, G.J. 1991. Stock price volatility: Some evidence from an ARCH model. Journal of Futures Markets 11 (April): 191-200.

Becketti, S., and Roberts, D. J. 1990. Will increased regulation of stock index futures reduce stock market volatility?. Economic Review 75 (November/December): 33-46.

Berndt, E.K.; Hall, B.H.; Hall, R.E.; and Hausman, J.A. 1974. Estimation and inference in nonlinear structural models. Annals of Economic and Social Measurement 4: 653-665.

Bollerslev, T. 1986. Generalized autoregressive conditional heteroscedasticity. Journal of Econometrics 31 (April): 307-327.

Bollerslev, T. 1987. A conditional heteroskedastic time series model for speculative prices and rates of return. The Review of Economics and Statistics 69 (August): 542-547.

Bollerslev, T., and Wooldrige, J.M. 1992. Quasi-maxium likelihood estimation and inference in dynamic models with time varying covariances. Econometric Reviews 11: 143-172.

Bollerslev, T.; Engle, R.; and Nelson, D. 1994. ARCH models. In R.F. Engle and D. MacFadden (eds). Handbook of Econometrics. Vol.IV. Amesterdam.

Brorsen, B. W. 1991. Futures trading, transaction costs, and stock market volatility. Journal of Futures Markets 11 (April): 153-163.

Brown, M.B., and Forsythe, A.B. 1974. Robust test for equality of variances. Journal of the American Statistical Association 69: 364-367.

Chatrath, A.; Ramchander, S.; and Song, F. 1998. Speculative activity and stock market volatility. Journal of Economics and Business 50 (July/August): 323-337.

Cheung, Y-W., and Fung, H-G. 1997. Information flows between eurodollar spot and futures markets. Multinational Finance Journal 1 (December): 255-271.

Duque, J.; Ranzina, F.; and Sampaio, A. I. 1998. The impact of start trading futures contracts in the Portuguese derivatives exchange. Presented at the 1 st Annual Conference of the Bolsa de Derivados do Porto. Porto: Portugal, 1999.

Edwards, F. R. 1988 [a]. Does futures trading increase stock market volatility?. Financial Analysts Journal 44 (January/February): 63-69.

Edwards, F. R. 1988 [b]. Futures trading and cash market volatility: stock index and interest rate futures. Journal of Futures Markets 8 (August): 421-439.

Engle, R. 1982. Autoregressive conditional heteroscedasticity with estimates of the variance of U.K. inflation,. Econometrica 50: 987-1008.

Eviews. 1998. Eviews User's Guide. Quantitative Microsoftware. 2nd Edition (1994-1998).

French, K.; Schwert, G. W.; and Stambaugh, R. 1987. Expected stock returns and volatility. Journal of Financial Economics 19: 3-29.

Galloway, T. M., and Miller, J.M. 1997. Index futures trading and stock return 
volatility: evidence from the introduction of mid-cap 400 index futures. The Financial Review 32 (November): 845-865.

Greene, W. H. 1997. Econometric Analysis. New Jersey: Prentice-Hall International Editions.

Grossman, S. J. 1988. Program trading and market volatility: A report on interday relationships. Financial Analysts Journal 44 (July/August): 18-28.

Harris, L. 1989. S\&P 500 Cash Stock Price Volatilities. Journal of Finance 44 (December): 1155-1175.

Hodgson, A., and Nicholls, D. 1991. The impact of index futures markets on Australian share market volatility. Journal of Business Finance \& Accounting 18 (January): 267-280.

Hogan, K. C. J.; Kroner, K. F.; and Sultan, J. 1997. Program trading, nonprogram trading, and market volatility. Journal of Futures Markets 17 (October): 733-756.

Jarque, C. M., and Bera, A.K. 1980. Efficient tests for normality, homocedastiticy and serial independence of regression residuals. Economic Letters 6: 255-259.

Laatsch, F. E. 1991. A note on the effects of the initiation of major market index futures on the daily returns of the component stocks. Journal of Futures Markets 11 (June): 313-317.

Lee, S. B., and Ohk, K. Y. 1992. Stock index futures listing and structural change in time-varying volatility. Journal of Futures Markets 12 (October): 493-509.

Levene, H.. 1960. Robust tests for equality of variances. In Olkin, I.(ed.). Palo Alto: Stanford University Press.

Ljung, G., and Box, G. 1979. On a measure of lack of fit in time series models. Biometrika 65: 297-304.

Maberly, E. D.; Allen, D. S.; and Gilbert, R. F. 1989. Stock index futures and cash market volatility. Financial Analysts Journal 45 (November / December): 75-77.

Ross, S. 1989. Information and volatility: The no-arbitrage martingale approach to timing and resolution irrelevancy. The Journal of Finance 44 (March): $1-17$.

Scholes, M., and Williams, J. 1977. Estimating betas from nonsynchronous data. Journal of Financial Economics 5: 309-327. 